\title{
AFINAL, QUEM SOMOS NÓS? Processos identitários das pessoas com albinismo
}

\author{
AFTER ALL, WHO ARE WE? Identity processes of people with albinism
}

Rafaela Melo Magalhães*

\begin{abstract}
Resumo
O texto traz reflexões quanto aos processos identitários das pessoas com albinismo (PCA), buscando compreender como as pessoas com albinismo percebem a si mesmas? Quais significados ser albino/a tem para essas pessoas? Quais discursos afirmativos são acionados? Tais perguntas nortearam o impulso intelectual desta escrita. Como desdobramento de um doutorado em andamento, a etnografia é base metodológica. O contato com os/as interlocutores/as foi estabelecido por meio de redes sociais, inicialmente por interesses de socialização, ora da minha parte, ora da parte dos interlocutores, resultando em momentos de escuta, conversas, entrevistas e presença em espaços virtuais destinados exclusivamente às PCA. Busco partilhar o que elas consideram/veem/constroem como sua identidade por meio de suas narrativas e nas correlações entre os percursos de vida, as interações sociais, o encontro com outras PCA e as demarcações do discurso biomédico. Para tanto, estabeleço diálogo com Oliveira (2005) e Ciampa $(1987,2002)$ e desloco o entendimento para pensar a identidade como um processo, um fenômeno social, em constate retroalimentação do binômio igualdade/diferença e intimamente vinculados às relações de poder. Para as PCA, o encontro com outros iguais é elemento fundamental para que os processos assumam também caráter coletivo de reconhecimento social e identidade política. A condição de reflexões incipientes tende a sinalizar mais perguntas do que respostas, bem como o próprio andamento da pesquisa. Não sendo possível conclusões fechadas, mas sim, a abertura de caminhos reflexivos e teóricos.
\end{abstract}

Palavras-chave: pessoas com albinismo; processos identitários; coletividade; reconhecimento.

\begin{abstract}
The text reflects on the identity processes of people with albinism (PCA), seeking to understand: how do people with albinism perceive themselves?; what meanings does being albino/a have for these people?; which affirmative speeches are triggered? These questions guided the intellectual thrust of this writing research. the result of an ongoing doctorate, with ethnography as its methodological basis. Contact with the interlocutors was established through social networks, initially for socialization purposes, sometimes on my part, sometimes on the part of the interlocutors, resulting in moments of listening, conversations, interviews and presence in virtual spaces exclusive to PCAs. I attempt to share what they consider / see / build as their identity, through their narratives and in the correlations between life trajectories, social interactions, encounters with other PCA and the demarcations of biomedical discourse. For this I establish a dialogue with Oliveira (2005) and Ciampa $(1987,2002)$ which alters my understanding of identity as a process, a social phenomenon, in constant feedback from the equality / difference binomial and closely linked to power. relations. For the PCAs, the meeting with other equals is a fundamental element so that the processes also assume a collective character of social recognition and political identity. The condition of incipient
\end{abstract}

\footnotetext{
* Doutoranda do Programa de Pós-Graduação em Antropologia (PPGA/UFBA)/Brasil. Docente de Sociologia do Instituto Federal Baiano (IFBAIANO). Contato: rafaela.magalhaes@ifbaiano.edu.br.
} 
reflections tends to signal more questions than answers, as well as the progress of the research. It renders impossible closed conclusions, and opens up reflexive and theoretical paths.

Keywords: people with albinism; identity processes; collectivity; recognition.

Nós somos apenas vozes
Nós somos apenas nós
Por exemplo
Apenas vozes da voz
Somos nós, por exemplo
Apenas vozes da voz

Gilberto Gil (NÓS..., 1976)

\section{Notas preliminares}

Escrever sobre albinismo na perspectiva das ciências sociais não é tarefa das mais fáceis. A escassez de pesquisas sobre o tema para dialogar e o exercício constante de aproximação versus separação do campo/temática, que em termos de métodos parece simples, mas na prática constitui imensos desafios. Portanto, como premissas básicas, preciso alerta ao/a leitor/a que as reflexões aqui propostas não encerram em si o tema, ao contrário, abrem possibilidades de acréscimos, revisões, interações e sugestões.

O intuito é iniciar provocações quanto aos processos identitários das pessoas com albinismo $^{1}$ (de modo a tornar a leitura mais fluida, doravante, indicarei com PCA), na tentativa de esboçar sentidos e significados que nós atribuímos a nossas experiências e vivências enquanto pessoas "marcadas" ou "adjetivadas" pela nossa condição genética.

Ainda em notas, tornar-se fundamental assumir minha posicionalidade. Sou uma mulher com albinismo, com deficiência visual, do tipo subnormal e que carrego na minha trajetória fortemente a negritude, nos laços/constituições familiares, princípios e ancestralidade. Importante destacar que a negritude aqui referida está em consonância com o termo criado por Aimé Césaire em 1939, na dimensão da aquisição de uma consciência

\footnotetext{
${ }^{1}$ Faço a escolha pela terminologia "pessoa com albinismo". A referência a essa forma de nominar é fruto do movimento de pessoas com deficiência, doenças congênitas e/ou permanentes que buscam pela linguagem potencializar as condições humanas frente às "limitações" ou deficiência. Assim, usa-se, por exemplo, a terminologia pessoa com deficiência, pessoa com autismo, dentre outras. Tal nomenclatura foi reconhecida pela ONU em 2006 na convenção sobre os direitos das pessoas com deficiência e promulgado no Brasil em 2009.
} 
racial. $^{2}$ Minha produção intelectual ocupa tanto o espaço de disseminação de informações sobre as PCA, através do olhar das ciências sociais, quanto assume um papel político de propagar as múltiplas formas de vida que nós temos e que historicamente foram silenciadas.

Fazer parte de um grupo minoritário em poder, e no caso das PCA, minoritário também em quantidade, ocupar a dupla posição de ser uma pessoa com albinismo e uma pesquisadora e intelectual que estuda o albinismo enquanto fenômeno social humano, produzindo reflexões sobre esse grupo, traz desafios de um escrever eu-nós, sobre/com, para/de, em nome/a partir de. O qual exerço reconhecendo que não há como estabelecer fronteiras rígidas.

Convido-o/a a selar um pacto, silencioso, de percorrer este texto, deixando-se seduzir por essas aparentes contradições. Nesta escrita engajada e imbricada com o que eu sou, com o que somos, com o que aproxima as PCA e com o que nos afasta.

Esse "nós", a que me refiro, não contempla todas as pessoas com albinismo do Brasil, nem poderia. Somos diversos, e nossa voz não é unívoca. Esse "nós" engloba as pessoas que aceitaram partilhar suas histórias de vida e compor a paisagem desta escrita.

O presente texto traz escutas, olhares e reflexões quanto aos processos identitários das pessoas com albinismo; busco partilhar o que elas consideram/veem/constroem como sua identidade, por meio de suas narrativas e nas correlações entre os percursos de vida, as interações sociais, o encontro com outras PCA e as demarcações do discurso biomédico. Como as pessoas com albinismo percebem a si mesmas? Quais significados ser albino/a tem para essas pessoas? Quais discursos afirmativos são acionados? Tais perguntas nortearam o impulso intelectual desta escrita. Ressaltando que as reflexões incipientes sinalizam mais perguntas do que respostas. ${ }^{3}$

Múltiplas ausências sociais permeiam a história das PCA, falta de representatividade midiática, inexistência de política públicas no Brasil, ausência de dados sobre sua condição, e os poucos estudos dentro das ciências humanas tornam relevante as pesquisas sobre o tema,

\footnotetext{
${ }^{2}$ O termo negritude apareceu com esse nome pela primeira vez em 1939, no poema Cahier d'un retour au pays natal (Caderno de um regresso ao país natal), escrito por Aimé Césaire. Cf. Bernd (1984) e Césaire (2010).

${ }^{3}$ Parte das reflexões trazidas neste texto foram apresentadas de forma oral no $1^{\circ}$ Simpósio Internacional Extensionista das Pessoas com Albinismo: dimensões da política do existir. Disponível em: https://www.youtube.com/watch?v=6_IkR_bLHII\&t=3859s. Acesso em: 31 out. 2021.
} 
particularmente, os que ultrapassam os descritivos médicos/genéticos e buscam compreender o fenômeno do albinismo nas interações e relações sociais.

Como desdobramento de um doutorado em andamento, ${ }^{4}$ a base metodológica está em consonância com a etnografia em curso, com as entrevistas e conversas realizadas com PCA de diferentes estados brasileiros. ${ }^{5}$

A pretensão no doutorado é realizar uma etnografia centrada nas PCA da Bahia. No entanto, a participação no Movimento de Pessoas com Albinismo do Brasil tem possibilitado o contato e interação com PCA de diferentes estados, possibilitando um rico conjunto de materiais e registros que utilizarei neste escrito. A escolha dos colaboradores/as foi determinada pelo critério de autorização da transcrição das conversas realizadas. Não houve a determinação prévia de um perfil.

O contato foi estabelecido por meio de redes sociais, inicialmente por interesses de socialização, ora da minha parte, ora da parte dos interlocutores, resultando em conversas sem roteiros prévios. Após o ingresso no doutorado, partilhei da minha condição de pesquisadora sobre o tema em todos os grupos, redes e coletivos de PCA. Momento em que várias PCA manifestaram desejo de contribuir para a pesquisa. Após a análise e escolha de alguns registros que considerava relevantes para contribuir com as reflexões aqui apresentadas, estabeleci contato com os/as colaboradores/as para a autorização da partilha de suas narrativas; seis PCA registraram anuência, dos quais realizei entrevista semiestruturada gravada com três.

Em decorrência da pandemia do COVID 19 e das medidas de segurança e proteção a vida, como a necessidade de distanciamento social, a maior parte das interações tem sido mediada pelos recursos tecnológicos, como aplicativos/plataformas de reuniões virtuais, grupos e trocas de mensagens (por texto e áudio) por aplicativos, como WhatsApp, contato e ligações telefônicas.

\footnotetext{
${ }^{4}$ Desenvolvo desde 2019, no Programa de Pós-Graduação em Antropologia (PPGA/UFBA), pesquisa de doutorado, cujo título provisório é: "Percursos, vivências e experiências de pessoas com albinismo na Bahia", sob orientação do Prof. Dr. Vilson Caetano Junior.

${ }^{5}$ Para este artigo, alarguei a participação dos/das colaboradores/as para além das fronteiras geográficas dos que vivem na Bahia, e partilho dos relatos de PCA de diferentes estados. Como a pesquisa está ainda em processo de submissão ao Comitê de ética, identificarei os colaboradores/as por idade e identidade de gênero assumida por eles/elas. Os relatos partilhados são de fevereiro de 2020 até junho de 2021.
} 


\section{A identidade é o começo?}

De forma bem simplista, e recorrendo a um debate mais ontológico e filosófico, de certo que não. Os processos de identificação e construção de significados compartilhados que se desenvolvem ao curso da vida não são o início. A existência é precedente. Qualquer coisa só se dá depois da existência (HEIDEGGER, 2002). Se não tem existência, nada há. Não há morte, nem vida, nem identidades, nem albinismo. Entendo aqui, nesse atrevimento de diálogo com a filosofia, que a existência é algo que se dá... não algo estanque ou parado. Pode-se pensar na manutenção da existência. Ou como permanecer existindo?

Como as pessoas com albinismo podem/conseguem viver numa sociedade brasileira que não sabe - em termos gerais, ou para a maioria das pessoas — sobre a nossa existência? Como pensar numa vivência, cuja adjetivação de "ser albino, ser albina, ter albinismo" é esvaziada de significados e sentidos; ou para pensar em outro cenário, seu significado é quase sempre distorcido, equivocado, exótico.

Passei muitos anos sem saber quem eu era, as pessoas na rua me olhava estranho, me sentia feia e teve até um homem que disse que eu fedia, ficava andando e me cheirando o tempo todo. Outras pessoas diziam que eu era albina, mas se ser albina era ficar sendo malvista na rua, eu não queria ser albina não. Muito tempo mesmo assim, às vezes, nem queria sair na rua. (informação verbal). ${ }^{6}$

$\mathrm{Na}$ época do colégio eu era o diferente por ser albino, mesmo tendo um irmão albino, não converso muito sobre essas coisas. Era meio resolvido, nós é albino e pronto. Mas não é assim, né? Hoje sei tanta coisa sobre, que teria me ajudado muito lá atrás. Acho que teria sofrido menos. Hoje conheço um tantão de albinos e é mais fácil falar das coisas... (informação verbal). ${ }^{7}$

Os dois primeiros interlocutores são PCA, cujo contato estabeleci por meio das redes sociais, e nossas conversas têm sido majoritariamente pelo WhatsApp. A primeira é uma mulher adulta, que mora na Região Metropolitana de Salvador, e o segundo é um jovem que reside no interior de uma cidade do Rio Grande do Sul. No início das conversas, perguntei de forma livre, como foi a vida deles até aquele momento; é nesse contexto que emergiram as falas que apresentei acima.

\footnotetext{
${ }^{6}$ Mulher, 44 anos, interlocutora 1. Entrevista realizada em março de 2020.

${ }^{7}$ Homem, 24 anos, interlocutor 2. Entrevista realizada em 15 de abril de 2021.
} 
Mesmo em condições diferentes, a adjetivação albino/a esteve presente na vida dessas duas PCA, no entanto, essa indicação da sua característica ou condição não trazia significados positivos no primeiro caso, ou sentidos para conduzir a vida, no segundo.

Quando uma PCA é identificada pelo seu fenótipo como alguém diferente, haja vista que o tipo mais comum de albinismo ocasiona uma aparência de pele e cabelos bem claros, muito brancos, essa diferença marca a existência por um processo de identificação. Nas primeiras interações, entretanto, não implica que a PCA se reconheça enquanto albino/a. Por vezes, essa adjetivação é esvaziada de significados e sentido para essas pessoas, mas ao mesmo tempo, é essa marcação da diferença que inicia um processo de cuidados. Esses cuidados garantirão que as pessoas com albinismo permaneçam existindo. Tanto na dimensão física - estar vivo - quanto nas interações e relações sociais. Em certa medida, para as PCA o processo de ser identificado/a enquanto albino/a serve a existência. Na dimensão física para desenvolver cuidados de proteção ao sol, e na dimensão social, despertar processos de entendimento da própria condição de ser uma PCA.

O desconhecimento social sobre nós perpassa não apenas as relações interpessoais, mas também as estruturas e instituições. No Brasil, quando uma criança nasce com albinismo, na maioria das maternidades, não há um aconselhamento para seus pais e responsáveis sobre suas especificidades. A probabilidade é imensa de que ela saia da maternidade sem que seus familiares saibam que ela é uma criança com albinismo. Não existe no Brasil uma linha de cuidado, vinculada ao SUS, de atenção e saúde das PCA.

\footnotetext{
Minha mãe fala que quando nasci foi um susto. Pois vim branquinha, bem branquinha e lá em casa era todo mundo moreno. Não teve ninguém para explicar nada pra ela. Ela disse que como foi parto normal [risos] e ela viu assim, eu saindo [risos] ela disse, é minha filha mesma. Me dá aqui essa galega que eu vou levar pra casa (informação verbal 1). ${ }^{8}$
}

O nascer de uma criança com albinismo num contexto de falta de informação e orientação ocasiona muitas dificuldades e dúvidas para os familiares, que na maioria das vezes, não obtêm informação alguma sobre a condição do seu filho/a. Esse cenário é muito comum a outras PCA, marcando ausências desde o nascimento, e que, por vezes, são "sanadas" somente na vida adulta.

\footnotetext{
${ }^{8}$ Interlocutora 1. Entrevista realizada em janeiro de 2021.
} 
Quando essa criança com albinismo passa pelas suas primeiras consultas médicas, na área da pediatra, até se diz que ela é uma criança albina, mas as informações tendem a ser desencontradas. E muitas vezes, as orientações são carregadas de um discurso biomédico ${ }^{9}$ limitador, marcado pelo "não vai conseguir", conforme relato abaixo:

Minha mãe e minha avó, não tive pai assim, me levaram a vários médicos quando era pequena, criança. E eles não davam assim esperança que eu teria uma vida normal. Disseram que não conseguiria nem ler, nem aprender. Minha mãe fala que ficou apavorada. Qual mãe quer ouvir uma coisa dessa? (informação verbal). ${ }^{10}$

Em um encontro virtual, perguntei à interlocutora 4, moradora da cidade de Aracaju, estado de Sergipe, que atualmente trabalha na área de vendas e recentemente começou a conhecer outras PCA, quais as memórias ela possuía sobre discurso de médicos na sua trajetória. Dentre outras questões, ela revela a narrativa de que desde o seu nascimento, sua mãe foi em busca de informações sobre sua condição e que encontrou poucas afirmações positivas sobre o futuro da sua filha.

Na minha experiência de vida, essa situação também ocorreu. Aos três anos de idade, meus pais já haviam buscado pelo menos dez médicos diferentes para entender minhas características. Um deles, pediatra de Salvador, reconhecido pela competência profissional, disse aos meus pais que eu teria que viver isolada de todas as pessoas, que inclusive era "absurdo" minha mãe sair comigo "naquelas condições", que eu deveria ficar num quarto escuro, sem nenhum feixe de sol e que só à noite eu poderia ficar fora desse quarto. Esse relato era sempre rememorado pela minha mãe a cada nova conquista da minha vida, seja ela profissional, acadêmica ou pessoal.

A projeção da perspectiva de um futuro para as PCA, na lógica discursiva de alguns profissionais, traduz fortemente o que o disciplinamento dos corpos pode ocasionar de futuro para uma pessoa fora do padrão.

Nas sociedades modernas, como bem salienta Foucault (2008), os discursos biomédicos se constituem como discursos normativos, ou seja, estabelecem o que é a norma e por consequência o que é normal. Direcionam para os corpos "um olhar" vigilante, controlador, absoluto. De modo que práticas de exclusão e anulação tendem a ser

\footnotetext{
${ }^{9}$ Campo de saberes biológicos no qual se baseia a medicina, incluem as instituições e as práticas de saúde, bem como as noções de doença.

${ }^{10}$ Mulher, 30 anos, interlocutora 4. Entrevista realizada em março de 2021.
} 
direcionadas para corpos e comportamentos que não se enquadram na normalidade estabelecida.

Considera-se normal, por vezes, o que aparece com mais frequência na sociedade. Mas a valorização da norma como padrão, contribuirá, no contexto de poder disciplinador, na associação entre o anormal e o patológico como sendo da mesma natureza. (CANGUILHEM, 2006). Para os corpos/pessoas com albinismo, condição genética rara e, portanto, pouco frequente, suas experiências de vida caminham sob a égide do discurso "anulador" da incapacidade, da inconformidade, da anormalidade.

As tecnologias políticas do corpo e da micropolítica do poder (FOUCAULT, 2010) condicionam pensar em corpos "normais", saudáveis e aceitáveis, punindo (seja pelo viés medicamentoso ou do confinamento) os corpos que estão "fora" desse padrão. Não é incomum para as PCA terem atribuídas às suas existências, deficiências/limitações cognitivas, intelectuais, comportamentos que não têm relação com a falta de pigmentação, mas que, discursivamente, tornam esse corpo impróprio para o convívio social.

No acesso à escola, pouco da condição visual das PCA é considerada (a maioria das PCA apresentam deficiência visual caracterizada pela baixa visão), ${ }^{11}$ e isso vai implicar em questões sérias no seu processo de aprendizagem. Por um lado, a dificuldade de aprendizagem decorrente de não conseguir enxergar as informações registradas no quadro, no caderno ou por meio de outros recursos. Por outro, o desconhecimento materializa-se em termos de palavrões, xingamentos, piadas e ofensas que marcam um percurso solitário. Muito possivelmente essa PCA será a única albina da sua turma, da sua escola, da sua faculdade, do seu ambiente de trabalho.

\footnotetext{
O pior momento foi o ensino fundamental, não enxergava o quadro e por isso, não aprendia o conteúdo, aí ia muito mal nas provas e era chacotado como burro, porque não aprendia. Era o albino burro. (informação verbal). ${ }^{12}$
}

$\mathrm{Na}$ escola foi onde sofri os piores preconceitos, era chamada de tudo que era nome, leite azedo, coisa nojenta, branquela fedida, barata d'agua, falava com a professora. Mas ela não sabia explicar para os outros que eu era albina (informação verbal). ${ }^{13}$

\footnotetext{
11 A ausência e/ou a síntese baixa de melanina afetam a anatomia dos nervos ópticos e comprometem o desenvolvimento adequado da fóvea, uma importante região da retina, causando transtornos significativos na visão.

${ }^{12}$ Interlocutor 2. Entrevista realizada em 15 de abril de 2021.

${ }^{13}$ Interlocutor 4. Entrevista realizada em março de 2021.
} 
Situações como as destacadas pelos/as colaboradores/as contribuem para a evasão escolar das PCA, creditadas, de forma errônea, a uma baixa capacidade cognitiva ou falta de inteligência. Quando o que existe é uma inadequação do sistema de ensino para lidar com a dificuldade visual extrema que as PCA possuem e a incompreensão da sua condição.

O desconhecimento sobre as pessoas com albinismo perpassa várias dimensões da sua existência. Como diz Oliveira (2005, p. 14): “Por 'conhecimento' de uma pessoa entendemos exprimir sua identificação enquanto indivíduo [...]”. No momento em que não há conhecimento sobre sua condição e sobre suas potencialidades, nega-se o sujeito.

Dentro da minha família, da minha escola, sempre fui a única. Saí de ser uma criança fofinha para os insultos e xingamentos na escola. Mesmo a professora falando que eu era albina, não sabia o que era assim, sentia só um vazio, sabe? Como se não fosse para estar ali, sabe? Não fosse para estar em lugar nenhum (informação verbal). ${ }^{14}$

Investigar sobre os processos identitários não é conduzir toda e qualquer explicação de ser/existir das PCA por essa via. Mas é salientar o que é recorrente nas narrativas partilhadas. A significação de ser uma pessoa com albinismo, o entendimento da especificidade da sua condição é, por vezes, a garantia de uma existência física.

Tomei tanto sol, tanto sol que fui parar no hospital. Fiquei cheio de bolhas. Fiquei na roça com meus irmãos o dia quase todo. De noite tive até febre. Minha mãe correu pro hospital, chegou lá os médicos brigaram muito com a minha mãe, não era pra eu tomar sol. Disseram que era albina e que o sol era meu inimigo. Daí minha mãe não deixava eu ir pra roça mais, só de tardinha. [...]Tirei um monte de câncer já, hoje uso protetor solar todo dia agora e não pego mais sol de jeito nenhum, quero ficar viva (informação verbal). ${ }^{15}$

Os dois trechos partilhados da narrativa da história de vida da interlocutora 5, mulher nordestina, do Rio Grande do Norte - "mulher arretada", como ela se define - mostram duas dimensões de ter albinismo e das existências. Primeiro, no significado do vazio presente na sua fala; um vazio que não era preenchido nem com explicações, nem com sentidos positivos. Sua marcação era de inferiorização, mediada por situações de preconceito e discriminação, e outra dimensionalidade está relacionada diretamente à necessidade de proteção solar adequada para garantir a vida física.

\footnotetext{
${ }^{14}$ Mulher, 47 anos, interlocutora 5. Entrevista realizada em 6 de junho de 2021.

${ }^{15}$ Idem.
} 
Essa interlocutora passou a conhecer outras PCA durante a pandemia. Ela começou a me seguir no Facebook, pois, segundo disse, achava-me bonita, e desde então conversamos muito sobre sua história de vida. Oriunda de uma família economicamente empobrecida, com mais três irmãos/primos pigmentados, cuja família passou anos morando no interior em comunidades consideradas rurais. Boa parte do nosso contato se dá por intermédio da troca de áudios pelo WhatsApp, já que ela apresenta dificuldades visuais mais graves, agravadas pela falta de atendimento adequado ao longo da vida. Atualmente, ela participa também de outros grupos de PCA nas redes sociais.

Ela passou por um processo de enfrentamento de um câncer, realidade que não é exceção nas histórias de vida das PCA. Embora não haja estatísticas oficiais, a trajetória no Movimento de luta das PCA nos permite assumir que ainda é alto o índice de PCA que morrem, antes dos 40 anos, em virtude do câncer de pele. ${ }^{16}$ Os motivos principais são o desconhecimento da sua condição, a falta de informação e, consequentemente, falta de cuidados adequados na exposição solar. Sendo a região Nordeste a que apresenta o maior número de casos conhecidos. ${ }^{17}$

Preencher de significados e pertencimentos a condição genética de ser uma pessoa com albinismo é permanecer existindo.

Desde pequena sabia que era albina. Minha mãe teve um tio distante da família que também era albino. Daí ela sabia, que eu não podia ficar no sol. mas só me entendi como albina quando já era adulta. Quando descobri que tinham outras pessoas iguais a mim (informação verbal). ${ }^{18}$

\section{Identidade como processo}

Nas humanidades — área de conhecimento — há um vasto debate em torno das identidades, sua conceituação, significado, contextualização e problemática. Podemos citar

16 A ausência de pigmentação implica numa ausência total de proteção contra os raios ultravioletas, ocasionado precocemente todos os efeitos danosos da exposição à radiação solar, como o eritema solar, o fotoenvelhecimento, lesões pré-malignas e malignas, queimaduras de graus variados e alto risco de câncer de pele.

${ }^{17}$ No mês de abril de 2021, na Bahia, morreram duas pessoas com albinismo por consequência do câncer de pele. Informações partilhadas por meio de grupos de WhatsApp e nota emitida pela APALBA em 23 de abril de 2021.

18 Texto descritivo partilhado em um grupo de WhatsApp exclusivo para PCA, escrito por mulher, 35 anos. Acessado em 12 de julho de 2020. 
valiosos estudos que compõem os trabalhos de Goffman (1988), Oliveira (1976, 2005), Barth (1998), Berger e Luckman (1999) e Ciampa (1987, 2002). A lista não se encerra nos autores apontados, mas tais estudos permitem uma aproximação com questões relevantes. Podemos ainda acrescentar o importante trabalho de Hall (2002) que desloca a identidade para um conceito mutável e posicional. Os sujeitos possuem, portanto, múltiplas identidades que se configuram e se reconfiguram nos sistemas sociais dos quais fazem parte.

Apesar de não haver unanimidade, nem claras definições sobre o conceito de identidade, o campo teórico indicado demonstra uma produção significativa nesse campo, não cabendo a este artigo a busca de mais uma definição, nem mesmo a escolha de uma vertente única. E sim, o reconhecimento de que muitas das questões abordadas ainda estão em voga nas experiências e vivências sociais. De certo que a amplitude e o uso irrestrito da ideia de identidade (tanto academicamente como pelas mídias e pelo senso comum) acabam, por vezes, a diminuir ou reduzir o fenômeno às características descritivas e deterministas para definir pertenças e grupos perdendo, em partes, as demais dimensões que o compõem.

Para as análises aqui propostas, desloco o entendimento para pensar que a identidade é um processo, um fenômeno social em constate retroalimentação do binômio igualdade/diferença, e intimamente vinculados às relações de poder. Portanto os processos identitários e suas dinamicidades são o "norte" nesse diálogo.

Cabe também situar que os processos de identificação estiveram ora atrelados a determinados atributos, como cor de pele, gênero, nacionalidade, e que, portanto, definiriam as identidades e, por consequências, os grupos de uma forma estanque e pouco maleável.

Ao pensar processos identitários, tais atributos são vistos como marcadores produzidos nas dinâmicas sociais e nas relações de poder. Assim, interessa pensar os lugares que os marcadores "ausência de pigmentação" ou "albino/a" ocupam nos processos de identificação das PCA. E de que modos esses atributos compõem o nós e/ou demarcam o espaço dos "outros" nessas relações.

\section{Se encontrar no encontro: pertencimento e significados}

Uma das formas de existência que nós, pessoa com albinismo, encontramos é o encontro. É a coletividade. É o grupo. Tem sido frequente a narrativa de que as pessoas se 
"descobriram" albinas quando conheceram outros "iguais" a si. Seja de forma presencial, seja de forma virtual por meio de grupos do WhatsApp ou das redes sociais.

O eu-nós, sobre/com, para/de, em nome/a partir de, esses conjuntos binários constituem o que chamo aqui do encontro. Pois não se trata somente de uma partilha física, de ter contato com um outrem que é fisicamente parecido com você. Que é seu igual. Tratase de nesse encontro, encontrar a "si" mesmo/a.

\begin{abstract}
Poxa, mano, pra mim foi tudo conhecer outros albinos sabe, para que é assim mais jovem vê que dá pra fazer faculdade, que dá pra trabalhar, ter família e tudo. Porque nunca vi outro albino na minha cidade, aí ficava aí pô só tem eu? Agora não, tem [cita vários nomes de pessoas com albinismo] é tudo. Brinco que nasci de novo nesse ano [risos] tenho agora um monte de irmão/ irmã albina, tenho uma nova família né? (informação verbal). ${ }^{19}$
\end{abstract}

$\mathrm{O}$ encontro possibilita às $\mathrm{PCAs}^{20}$ acionarem outros modos de ver/ser no mundo. Nesse encontro de um "outro" que também sou eu, possibilita-se que apareça nova identidade, e o desenvolvimento de "identidade pós-convencionais" que se definam "pela aprendizagem de novos valores, novas normas, produzidas no próprio processo em que a identidade está sendo produzida, como mesmidade de aprender (pensar) e ser (agir)" (CIAMPA, 2002, p. 241).

Laços se fortalecem nas trocas com outras pessoas que vivem as mesmas experiências, e elas contribuem para que as pessoas com albinismo entendam mais sua própria história. Nos coletivos, nos grupos, no encontro, constata-se que quase sempre as histórias de vida são mais permeadas por semelhanças do que afastamentos, mesmo considerando diferentes territorialidades, como diferentes estados brasileiros.

É muito louco. Parecia que só eu passei por isso [risos] e agora vejo que todo mundo aqui tem histórias parecidas. Pô, legal mano (informação verbal). ${ }^{21}$

Eu passei muitos anos da minha vida sem ter contato com outras pessoas albinas, agora como adulta que tenho contato. Conheci pessoas nas redes sociais e participo de muito grupos de zap, converso mesmo, fiz amigos. Encontrei outros albinos,

\footnotetext{
${ }^{19}$ Fala de um jovem de 18 anos em uma roda de conversa com pessoas com albinismo. Roda de conversa realizada em 10 de junho de 2020, organizada para socialização de pessoas com albinismo que se conheceram por meio das redes sociais (grupos no Facebook).

${ }^{20}$ A partir desse momento acrescento um s, a sigla PCA por entender que após o encontro são fortalecidos os laços e o entendimento enquanto uma coletividade.

${ }^{21}$ Fala de um jovem de 18 anos em uma roda de conversa com pessoas com albinismo. O mesmo da nota 19.
} 
assim antes da pandemia. Aí minha ficha caiu sabe, agora sei muito, muito mais de mim. Sei o que realmente é ser albina. (informação verbal). ${ }^{22}$

Eu fiquei muito tempo andando só e de tantas coisas que eu sentia falta, ver a alguém para olhar e dizer, nossa! Essa pessoa aí parece comigo. Essa pessoa aí tem não só a pele parecida com a minha, mas tem coisas na vida dela legal que também tem na minha. E isso eu encontrei quando conheci outros albinos. Hoje tem várias pessoas com albinismo que eu conheço e penso, ah se ele conseguiu, eu também consigo. Você não faz ideia do quanto isso é importante, [Risos] quer dizer, faz $\operatorname{sim}$ (informação verbal). ${ }^{23}$

O jovem, cujas falas foram partilhadas em espaços de interação nos grupos exclusivos para PCAs, é do interior de São Paulo; dos colaboradores/as, foi com quem compartilhei o menor número de conversas, por incompatibilidade de horários e alguns esquecimentos (marcávamos encontros, e ele esquecia de comparecer). Ele conheceu outras PCAs pela primeira vez, ano passado, em 2020, e desde então, troca contatos e interage por meio das redes sociais com diversos grupos. Sempre demostrando muita euforia e felicidade por enxergar outras possibilidades para sua vida.

A interlocutora 6 é do estado de Maceió, mas ao longo da vida morou em várias localidades diferentes. Ela se reconhece enquanto uma missionária, e nas nossas conversas, perguntei sobre como conhecer outras PCAs modificou sua visão sobre si.

As sociabilidades dentre os iguais permite nos reconhecermos como pessoa, como capazes de ter relações sociais e pela diversidade que nos compõe. "E dentre essas pretensões, aquela que parece possuir um teor mais genérico é o reconhecimento de nós mesmos como pessoa, portanto como ser social” (OLIVEIRA, 2005, p. 15).

O nó desse "nós", talvez esteja nessa dupla dimensão da igualdade/diferença. Ao tempo que se estabelece pela diferença frente a outrem, tem a dimensão da igualdade junto à noção de pertencimento. Essa dupla dimensão é constatada por Ciampa: “Com isso se revela um dos grandes segredos da identidade: ela é a articulação da diferença e da igualdade" (1987, p.138).

O “eu” não se torna o outro. São preservadas as subjetividades e individualidades no processo. Esse encontro não significa que as semelhanças tornam todos as PCAs iguais. De forma alguma. Nos grupos de bate papo, nas reuniões dos coletivos, nos eventos sobre o tema,

\footnotetext{
${ }^{22}$ Mulher, 52 anos, interlocutora 6. Transcrição de áudios enviados pelo WhatsApp em maio de 2021.

${ }^{23}$ Interlocutor 4. Entrevista realizada em março de 2021.
} 
várias outras questões são acionadas (pertencimento racial, deficiência, sexualidade) no sentido de que as pessoas com albinismo precisam ser respeitadas também nas suas diferenças. $\mathrm{O}$ respeito às diferenças caminha atrelado ao respeito à diversidade da própria existência humana.

É preciso garantir, compreender e respeitar nossa diversidade. Pois ela é da condição do existir humano. Somos homens, mulheres, não binários, altos, baixos, gay, lésbicas, bi, queer, temos deficiência ou não. Somos de esquerda, de direita, jovens, crianças, somos pretos e brancos, asiáticos, indígenas. Sim, as pessoas com albinismo não são só brancas, elas também têm direto a assumir uma identidade racial que dialoga com sua história de vida. Somos, e pessoa com albinismo. Não só isso! E isso também. Nos relacionamos socialmente, amamos interagimos, construímos afetividades, erramos e aprendemos, para além da nossa condição genética, mas também com/por ela (informação verbal). ${ }^{24}$

A condição genética nos liga em alguns propósitos, todos/as colaboradores/as desta pesquisa, após $o$ encontro e a significação enquanto pessoa com albinismo, fizeram uma escolha: de atrelar sua existência a uma militância, um ativismo em prol da melhoria de vida de todas PCAs. Nesse processo, o eu-nós se torna também engajamento político. Disseminar informações, trocar experiências, produzir conhecimento, ocupar espaços e, principalmente mostrar que estamos aqui, vivos e existindo. A construção torna-se coletiva.

\section{A coletividade e o reconhecimento}

O albinismo se caracteriza como uma condição genética rara, não transmissível pelo contato que afeta a todos os animais, incluído nós humanos, e que se caracteriza na sua forma mais visível pela ausência de pigmentação da pele, dos pelos, cabelos e formação ocular, ocasionado frequentemente a baixa visão ou visão subnormal. Por conta desses aspectos, as pessoas com albinismo terão sensibilidade ao sol e, portanto, precisarão de cuidados específicos com a pele e com os olhos.

O albinismo consiste de um conjunto heterogêneo de distúrbios genéticos na síntese de melanina que podem levar à hipopigmentação da pele, dos pelos, cabelo e olhos. Essa condição resulta de alterações em um ciclo complexo de reações metabólicas que causam redução ou ausência congênita da produção de melanina.

[...] Uma das principais consequências do albinismo é a baixa visão, que pode estar

\footnotetext{
${ }^{24}$ Trecho de fala realizada por mim no $1^{\circ}$ Simpósio Internacional Extensionista das Pessoas com Albinismo: dimensões da política do existir. Disponível em: https://www.youtube.com/watch?v=6_IkR_bLHII\&t=3859s.
} 
reduzida de forma variável, a depender do tipo de albinismo e da quantidade de melanina ocular, não sendo rara uma acuidade medida como 20/200, que é considerada cegueira legal. A pessoa com albinismo pode apresentar diferentes graus de deficiência visual, [...]. Frequentemente ocorre estrabismo, com prejuízo na percepção de profundidade, pela falta de coordenação entre os olhos, fotofobia e nistagmo, devido aos movimentos rápidos e involuntários dos olhos na horizontal, o que também contribui para a baixa visão. (MOREIRA et al., 2007, p. $69-70)$.

Como as PCAs garantirão esses cuidados, se não forem informadas de como realizar de forma adequada a fotoproteção? Como garantir a total proteção, se as PCAs não tiverem como custear a quantidade de protetor solar que precisarão ao longo de uma semana, um mês ou um ano? Como garantir que os cuidados com a pele serão realizados de forma correta, se a maioria dos municípios do Brasil não tem a especialidade de dermatologia? Como cuidar e entender a baixa visão, se os oftalmologistas não estão preparados para lidar com essa especificidade, e a sociedade, de forma geral, tende a reconhecer a deficiência visual apenas se ela é a cegueira total?

$\mathrm{O}$ ativismo que decorre do encontro e que potencializa a ação individual em construção coletiva defende que só será possível responder às questões acima quando houver um amplo reconhecimento social brasileiro sobre as PCAs.

Por "reconhecimento" entendemos um ato expressivo com o qual este conhecimento está confirmado pelo sentido positivo de uma afirmação. Contrariamente ao conhecimento, que é um ato cognitivo não público, o reconhecimento depende de meios de comunicação que exprimem o fato de que outra pessoa é considerada como detentora de um "valor" social (OLIVEIRA, 2005, p. 14).

Esse reconhecimento está atrelado, em partes, à garantia de direitos. Nesse campo, ter reconhecido seu pertencimento a um dado grupo minoritário é passo fundante para estabelecer diálogos com os poderes públicos na busca e implementação de políticas que assistam as necessidades específicas das PCAs. Os processos identitários são também acionados de forma estratégica para garantir direitos.

Já que existimos, porque continuamos invisíveis para os poderes públicos? As pessoas com albinismo se encontram em vulnerabilidades, e isso demostra uma desigualdade. Temos menos acesso que as pessoas que têm cor à escola, ao trabalho, enfim. Precisamos de políticas públicas que de fato, efetivem nossos direitos (informação verbal). ${ }^{25}$

\footnotetext{
${ }^{25}$ Homem, 47 anos, interlocutor 3. Mensagem enviada pelo WhatsApp em setembro de 2020.
} 
Podemos citar Ciampa para pensar que a luta pelo reconhecimento faz emergir a identidade política que conjuga igualdade e diferença, e convergem em "lutas pela emancipação de diferentes grupos sociais, que em sua ação coletiva revelam velhas ou novas opressões" (CIAMPA, 2002, p. 139).

Nesse processo, o indivíduo compõe grupos, associações, ideias e causas que the possibilitem projetos de emancipação. No sentido de não mais estar "aprisionado" a políticas de identidade que o homogeneíze. Dessa maneira, esses espaços são locais possíveis para exercer a autonomia e exercer uma identidade política que permite alcançar uma igualdade em termos de direitos e do exercício de uma cidadania plena (CIAMPA, 2002).

$\mathrm{Na}$ perspectiva dos processos identitários que consideram as relações de poder, a identidade política pode ser também compreendida como "estratégias identitárias" (CUCHE, 2002), ações desenvolvidas pelos sujeitos de modo a melhor posicionalidade dentro das relações não iguais de acesso ao poder.

Como grupo historicamente invisibilizado e silenciando quanto às suas demandas e especificidades, o coletivo de PCAs, formado pela reunião dos sujeitos, constitui espaço de fortalecimento, trocas e demarcação de fronteiras.

Cabe, aqui, trazer mesmo que de forma breve, o empréstimo dessa categoria já utilizada por Barth (1998), ao pensar sobre os grupos étnicos e as demarcações e entendimentos sobre o que/quem compõe nosso grupo e sobre o que/quem são os outros. Assim, há a formação do grupo das PCAs em oposição aos grupo de pessoas sem albinismo. $\mathrm{Na}$ qual, o marcador social da diferença (falta de melanina) compõe os pertencimentos, as identificações e a afirmação de processos identitários de caráter político no reconhecimento das diferenças e na busca pela garantia de direitos.

\section{Considerações (não) finais}

A tentativa de um desenho teórico capaz de contribuir para a compreensão dos processos identitários das PCAs caminha mais próximo a contornos. Que talvez melhor compusesse textualmente estrutura de ensaio do que as exigências formais para um artigo. No entanto, o encontro também com outras leituras e interpretações desses contornos responde ao anseio inicial de aberturas para tratar dessa temática. 
As PCAs apresentam um corpo marcado pela diferença em decorrência da ausência de pigmentação e de uma aparência física pouco comum no Brasil. O desconhecimento de suas características e das consequências provocados pelo albinismo, confere a nós uma trajetória marcada por ausências e lacunas que se somam a uma sensação de incompletude e incompreensão das nossas existências. A escuta realizada com outras PCAs, e partilhada neste texto, permite apontar como caminho de ressignificação o encontro com outras PCAs.

Os processos identitários não são encerrados nesse encontro, ao contrário, apontamse novas possibilidades de pertencimentos, identificações, vivências e experiências que, entre outras dimensionalidades, denunciam enquanto grupo/coletivo relações desiguais de acesso ao poder.

Pertencer a um grupo minoritário possibilita que os pertencimentos sejam estrategicamente utilizados para demarcar posição de igualdade/diferença, e diante disso, assumir politicamente engajamentos que demarquem luta por direitos e garantia da equidade por meio de políticas públicas especificas para as PCAs.

Um dos entraves para a implantação de políticas púbicas para as PCAs é a falta de registro e informações sobre o quantitativo de pessoas por município, estado e, por fim, no território nacional. Atualmente não há nenhum dado oficial fornecido por nenhum meio de coleta de informação que indique esses quantitativos. Sendo essa pauta uma das principais levantadas pelo Movimento de Pessoas com Albinismo. ${ }^{26}$ Sem demarcação de público, não há como precisar questões orçamentárias.

Embora se tenha algumas estimativas de incidência do albinismo entre as populações: na razão de uma para 17 mil pessoas (dados europeus e norte-americanos), em se tratando de população mundial temos 1:20000. Prevalência que é aumentada nas populações africanas ou afrodiaspóricas, estimada em 1:10000, o que nos permite inferir que há uma quantidade maior de PCAs no Brasil do que em outros países (ROCHA; MOREIRA, 2007; BÍSCARO, 2012). Os dados que ainda prevalecem no Brasil são muito antigos, e têm por base estudos de Freire-Maia, datados de 1988, não sendo adequados para estimar e subsidiar as políticas.

\footnotetext{
${ }^{26}$ Atualmente não existe uma associação ou entidade nacional que represente as pessoas com albinismo. Neste ano, em abril, foi organizado um coletivo nacional de pessoas com albinismo por intermédio de grupos virtuais que têm realizado encontros periódicos para organizar e articular um movimento nacional. Uma das ações foi a realização no dia 29 de junho de 2021, da $1^{\circ}$ Audiência Pública na Câmara dos Deputados Federais para debater sobre política pública e atenção à pessoa com albinismo.
} 
Assim, é fundamental e urgente pesquisas, mapeamentos e censos que consigam dimensionar de forma efetiva o real quantitativo de PCAs no Brasil, de modo a construir políticas públicas que atendam às necessidades desse grupo social.

Os processos identitários de caráter político assumida/o pelas PCAs têm como projeto emancipatório transformar a sociedade brasileira para que os grupos minoritários gozem de vida plena, autonomia e respeito às suas especificidades. A condição genética de ser uma pessoa com albinismo nos aproxima enquanto pessoas de direito.

Mas não nos limita, não nos define!

\section{Referências}

BARTH, F. Grupo étnico e suas fronteiras. In: POUTIGNAT, Philippe, STREIFF, FERNART, J. Teorias da etnicidade. São Paulo: Editora Unesp, 1998. p. 187- 227.

BERGER, P. L.; LUCKMANN, T. A construção social da realidade. Petrópolis: Vozes, 1999. Original publicado em 1983.

BERND, Zilá. A questão da negritude. São Paulo: Brasiliense, 1984.

BÍSCARO, R. Escolhi ser albino. São Carlos: Editora EdUFSCar, 2012.

CANGUILHEM, Georges. O normal e o patológico. 6. ed. Rio de Janeiro: Forense Universitária, 2006.

CÉSAIRE, Aimé. Discurso sobre a negritude. In: CESAIRE, Aimé; MOORE, Carlos. (org.). Discurso sobre a negritude. Belo Horizonte: Nandyala, 2010. p. 107-114.

CIAMPA, A. C. Políticas de identidade e identidades políticas. In: DUNKER, C. I. L.; PASSOS, M. C. Passos (org.). Uma psicologia que se interroga: ensaios. São Paulo: Edicon, 2002. p. 133144.

CIAMPA, A. C. A estória do Severino e a história da Severina: um ensaio de psicologia social. São Paulo: Brasiliense, 1987.

CUCHE, D. A noção de cultura nas ciências sociais. 2. ed. Bauru: 2002.

FOUCAULT, M. O nascimento da clínica. 6. ed. Rio de Janeiro: Forense Universitária, 2008.

FOUCAULT, M. Vigiar e punir: nascimento da prisão. Petrópolis: Vozes, 2010.

FREIRE-MAIA N. Teoria da evolução: de Darwin a teoria sintética. Belo Horizonte. Editora Itatiaia. São Paulo, 1988.

GOFFMAN, E. Estigma: notas sobre a manipulação da identidade deteriorada. 4. ed. Rio de Janeiro: LTC, 1988.

HALL, S. A identidade cultural na pós-modernidade. 7. ed. Rio de Janeiro: DP\&A, 2002.

HEIDEGGER, M. Ser e tempo. Petrópolis: Vozes, 2002. 
MOREIRA, L.M de A. et al. Perfil do albinismo oculocutâneo no estado da Bahia. Revista de Ciências Médicas e Biológicas, Salvador, v. 6, n. 1, p. 69-75, 2007. Disponível em: http://www.portalseer.ufba.br/index.php/cmbio/article/view/4152/3033. Acesso em: 20 dez. 2020.

NÓS, por exemplo. Intérprete: Gilberto Gil. In: Doces Bárbaros ao vivo. Intérpretes: Caetano Veloso, Gal Costa, Gilberto Gil, Maria Bethânia. Rio de Janeiro: Philips, 1976. Disco de vinil. Faixa 10 , lado 2 .

OLIVEIRA, Roberto Cardoso de. Identidade, etnia e estrutura social. São Paulo: Pioneira, 1976.

OLIVEIRA, Roberto Cardoso de. Identidade étnica, reconhecimento e o mundo moral. Revista Anthropológicas. Recife, v. 16, n. 2, p. 9-40, 2005. Disponível em: https://periodicos.ufpe.br/revistas/revistaanthropologicas/article/view/23631. Acesso em: 31 out. 2021.

ROCHA, L. de M.; MOREIRA, L.M. de A. Diagnóstico laboratorial do albinismo oculocutâneo. Jornal Brasileiro de Patologia e Medicina Laboratorial. Rio de Janeiro, v. 43, n. 1, p.25-30, 2007. Disponível em: https://www.scielo.br/j/jbpml/a/KmSWk6MzkQFHQxBrzvhhFxq/?format $=$ pdf\&lang=pt. Acesso em: 4 nov. 2021.

Recebido em: 19/07/2021.

Aceito em: 25/10/2021. 